\section{Algebraic Plane Curves}

A Treatise on Algebraic Plane Curves. By Prof. J. L. Coolidge. Pp. xxiv + 513. (Oxford: Clarendon Press ; London: Oxford University Press, 1931.) 30s. net.

THe HERE was a time, not so very long ago, when the words geometry and mathematics were almost synonymous, To-day the pure mathematicians, in every country except one, are nearly always analysts; even the minority who still call themselves geometers generally occupy themselves with some of the differential aspects, avoiding diagrams and filling their pages with symbols, as if they felt that their continued existence depended upon conforming as much as possible to the fashions prescribed by the all-powerful analysts. But we need not despair ; rare animals have been saved from extinction by measures of protection taken just in time, and now Prof. J. L. Coolidge comes to the assistance of algebraic geometers with a book written in the spirit of and dedicated to the geometers of Italy, the only land in which they still flourish.

There is a great need for such a book, for Salmon's great work has long been obsolete, belonging to an age that knew nothing of Nöther's fundamental theorem and was content with a naïve process of counting constants. Recent English books give a good account of curves of the third and fourth order or other special topics, but they have very little about general theorems. Perhaps the best account of general methods is given in Severi-Löffler's "Vorlesungen über algebraische Geometrie", but this omits many important parts of the theory, and Severi's "Geometria algebraica" has as yet reached only its first volume.

Prof. Coolidge's treatment is very extensive, so far as the general theory is concerned. His only important omissions are just those special topics which are readily accessible elsewhere. It is useless to look here for the properties of the bitangents of a quartic, but there is something about curves classified by their genus, such as rational curves, elliptic curves, and so forth. The emphasis is on Nöther's theorem (now the foundation of the subject), Plücker's equations, Cremona transformations, and the theory of correspondences (treated in a special case by Chasles, discovered intuitively by Cayley, and first proved by Brill). A useful feature is the inclusion of a brief treatment of invariants, including the Aronhold symbolic notation, which is used later in dealing with apolarity. The notation of the tensor calculus is also used, though not very often.

In studying linear series of point-groups on a curve, much use is made of Abelian integrals, the leading properties of which are briefly explained. At this point the analysts will chuckle. There seems no reason why algebraic geometers should not be able to work out all about algebraic correspondences by strictly algebraic methods, but the melancholy fact is that they cannot; and up to the present they continue to upset the already unfavourable balance of trade between geometry and analysis by importing devices foreign to their subject, such as Abelian integrals.

There are a few minor points upon which the book seems open to criticism. The frequent avoidance of homogeneous co-ordinates by using unity as a variable and differentiating with respect to it is admitted to be "rather bizarre" (p. 7) and a "curious trick" (p. 12). The definition of circular points at infinity (p. 14) appears artificial, and moreover contains an unfortunate misprint which may puzzle a beginner. The treatment of asymptotes could have been improved. But on the whole, the book will be of great use to students in providing a source, perhaps the only accessible source, of a subject which, though at present unfashionable, must remain one of the "invariants, matters of abiding interest and importance, which deserve to be always held in honour".

\section{H. T. H. Piaggio.}

\section{Ethnology of Mysore}

The Mysore Tribes and Castes. By the late H. V. Nanjundayya and Rao Bahadur L. K. Ananthakrishna Iyer. Vol. 4: K-V. Pp. $\mathrm{x}+677+68$ plates. (Published under the auspices of the Mysore University.) (Bangalore : Mysore Government Press, 1932.) 12.8 rupees ; $20 s$.

R. ANANTHAKRISHNA IYER and his late I colleague have now supplied us with the third of the four volumes in which the castes and tribes of Mysore are described on the lines laid down in 1902 for the Ethnographic Survey of India. The first volume, which is to be issued last and will summarise the contents of the other three, will be awaited with special interest.

The present volume presents two specially noteworthy features. It contains an account of the Lingāyats, that un-Brahmanic Hindu community numbering many millions which presents the remarkable aspect of a reform movement starting on 